\title{
Magnetic resonance spectroscopy analysis of intramyocellular lipid composition in lipodystrophic patients and athletes
}

David B Savage ${ }^{1}$, Laura Watson ${ }^{2}$, Katie Carr ${ }^{2}$, Claire Adams ${ }^{1}$, Soren Brage ${ }^{3}$, Krishna K Chatterjee ${ }^{1,2}$, Leanne Hodson ${ }^{4}$, Chris Boesch ${ }^{5}$, Graham J Kemp ${ }^{6}$, Alison Sleigh 1,2,7

${ }^{1}$ Metabolic Research Laboratories, Wellcome Trust-MRC Institute of Metabolic Science, Cambridge Biomedical Campus, Cambridge, United Kingdom.

${ }^{2}$ National Institute for Health Research/Wellcome Trust Clinical Research Facility, Cambridge University Hospitals NHS Foundation Trust, Cambridge Biomedical Campus, Cambridge, United Kingdom.

${ }^{3}$ MRC Epidemiology Unit, University of Cambridge, School of Clinical Medicine, Cambridge, United Kingdom.

${ }^{4}$ Oxford Centre for Diabetes, Endocrinology and Metabolism (OCDEM), Radcliffe Department of Medicine, University of Oxford, Oxford, United Kingdom.

${ }^{5}$ Department of Clinical Research and Radiology, AMSM, University Bern, Bern, Switzerland.

${ }^{6}$ Department of Musculoskeletal Biology, University of Liverpool and MRC-Arthritis Research UK Centre for Integrated research into Musculoskeletal Ageing (CIMA), Liverpool, United Kingdom.

${ }^{7}$ Wolfson Brain Imaging Centre, University of Cambridge School of Clinical Medicine, Cambridge, United Kingdom.

Short title: IMCL composition and insulin sensitivity

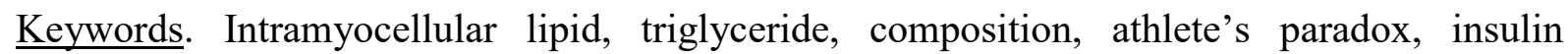
sensitivity, magnetic resonance spectroscopy.

Correspondence and Reprint Requests: A. Sleigh, Box 65 Addenbrooke's Hospital, Hills

Road, Cambridge, CB2 0QQ, United Kingdom. Email. as626@cam.ac.uk

Disclosure Summary: The authors have nothing to disclose. 


\section{$1 \quad$ Abstract}

2 Context: Paradoxically, intramyocellular lipid (IMCL) accumulation has been linked to both

3 insulin-resistant and to insulin-sensitive (athletes) states. The composition of this lipid store is

4 unknown in these states.

5 Design and Methods: We used a recently validated and potentially widely applicable ${ }^{1} \mathrm{H}$ magnetic resonance spectroscopy method to compare the compositional saturation index $\left(\mathrm{CH}_{2}: \mathrm{CH}_{3}\right.$ ratio) and concentration independent of composition $\left(\mathrm{CH}_{3}\right)$ of intramyocellular lipid in the soleus and tibialis anterior muscles of 16 female insulin-resistant lipodystrophic patients with that of age- and gender- matched athletes $(n=14)$ and healthy controls $(n=41)$.

10 Main Outcome: IMCL compositional saturation index $\left(\mathrm{CH}_{2}: \mathrm{CH}_{3}\right.$ ratio).

11 Results: The IMCL $\mathrm{CH}_{2}: \mathrm{CH}_{3}$ ratio was significantly higher in both muscles of the 12 lipodystrophic patients compared with age- and gender-matched controls but not compared to athletes. IMCL $\mathrm{CH}_{2}: \mathrm{CH}_{3}$ was dependent on IMCL concentration in the controls and after adjusting the composition index for quantity $\left(\mathrm{CH}_{2}: \mathrm{CH}_{3 \text { adj }}\right)$ was able to distinguish patients from athletes. With groups pooled, this $\mathrm{CH}_{2}: \mathrm{CH}_{3 \text { adj }}$ marker had the strongest relation to 16 insulin resistance (HOMA-IR) compared to other measures of lipid concentration and composition, especially in the soleus muscle. Contrary to the 'athlete's paradox', IMCL in athletes was similar in tibialis anterior $(p>0.05)$ and significantly lower in the soleus $(p<$ 0.004) compared to both controls and patients.

Conclusions: The IMCL saturation index adjusted for quantity, which likely reflects 21 accumulation of saturated IMCL, is more closely associated with insulin resistance than concentration alone. 


\section{Introduction}

Following the demonstration that ${ }^{1} \mathrm{H}$ magnetic resonance spectroscopy $\left({ }^{1} \mathrm{H}\right.$ MRS) can noninvasively distinguish intramyocellular (IMCL) from extramyocellular (EMCL) lipids $(1,2)$, associations were reported between soleus IMCL accumulation and insulin resistance (IR) independent of fat mass (3-5). Given that skeletal muscle accounts for a significant amount of insulin-stimulated glucose disposal and thus represents the primary site for postprandial glucose disposal (6), these findings were of considerable physiological interest. Furthermore these data strongly supported the link between ectopic fat accumulation and insulin resistance $(7,8)$. Although it soon became clear that triglycerides themselves were unlikely to be involved in causing insulin resistance, intramuscular triglyceride content does appear to correlate with insulin resistance in some states $(5,9-12)$. One particularly striking and surprising exception to this was reported in athletes, where histological studies suggested that neutral lipid accumulation was a feature of skeletal muscle in insulin-sensitive trained athletes $(13,14)$, and this has led to the now widely cited notion of an 'athlete's paradox' $(13)$. This concept is consistent with the idea that triglyceride itself is not involved in causing insulin resistance and has prompted several efforts to identify the lipid intermediates responsible for causing insulin resistance or preserving the insulin sensitivity of athletes.

Saturated fat has been implicated in the pathogenesis of metabolic disease $(15,16)$ and we have recently described and validated (using IMCL/EMCL simulated phantoms of known composition) a ${ }^{1} \mathrm{H}$ MRS method that provides an in vivo compositional marker of IMCL that primarily reflects the degree of saturation of the fatty acid chains within triglyceride (17). This marker, which we call the 'IMCL saturation index' $\left(\mathrm{CH}_{2}: \mathrm{CH}_{3}\right)$, utilizes good quality spectra acquired at $3 \mathrm{~T}$ with short echo time and compares the $\mathrm{CH}_{2}$ resonance located at 1.3 ppm (which is influenced by both concentration and composition), with that of the $\mathrm{CH}_{3}$ 
resonance at $0.9 \mathrm{ppm}$ which is independent of triglyceride composition: this is illustrated in

Figure 1. From this figure it can also be seen that using concentration of ' $\mathrm{H}$ ' that resonate at

far, confounds the contributions of both the concentration of lipid and its composition. This has potential for significant error in the estimation of concentration: the composition could contribute as much as $43 \%$ to the observed signal, which is equivalent to a $77 \%$ theoretical increase in signal if the pool was stearic acid instead of sunflower oil. We therefore use the IMCL $\mathrm{CH}_{3}$ peak at $0.9 \mathrm{ppm}$ to estimate the total concentration of IMCL, as this is independent of the degree of saturation of the fatty acid chains within triglyceride (i.e. composition). We call this the composition-independent IMCL concentration estimate, to distinguish it from the conventional estimate using $\mathrm{CH}_{2}$.

Lipodystrophy is a rare cause of severe IR and is typically characterized by prominent ectopic fat accumulation due both to the reduction in adipocyte lipid storage capacity and the associated hyperphagia induced by leptin deficiency. In order to ascertain if intramyocellular lipid composition is altered in lipodystrophic (LD) patients, and if such changes in lipid composition might help to elucidate the 'athlete's paradox', we determined the compositional saturation index $\left(\mathrm{CH}_{2}: \mathrm{CH}_{3}\right.$ ratio) and composition-independent concentration (from $\left.\mathrm{CH}_{3}\right)$ of IMCL in the soleus and tibialis anterior muscles of female insulin-resistant lipodystrophic patients, as well as age- and gender-matched athletes and non-athlete controls. 


\section{Material and Methods}

\section{Participants}

Sixteen female patients with lipodystrophy were identified as part of a long-standing study of human IR syndromes, while age- and gender-matched controls $(n=41)$ and athletes $(n=14)$ were recruited by advertisement. Soleus IMCL data from five of the patients were included in a previously published study (18). Control and athlete exclusion criteria included smoking, drug or alcohol addiction, any current or past medical disorder or medications that could affect measurements including supplements such as creatine, and standard MR contraindications. Controls were recruited who exercised less than 3 times per week for 1 hour each time, whilst the athletes were part of a running club, some at international level, and all ran distances between 10 and $40 \mathrm{~km}$ regularly. The patient studies were approved by the National Health Service Research Ethics Committee, the healthy volunteer studies by East of England Cambridge Central Ethics Committee. Studies were conducted in accordance with the Declaration of Helsinki and all participants provided written informed consent.

\section{Protocol}

Volunteers were instructed to follow normal dietary habits for 3 days prior to arrival at the Cambridge NIHR/Wellcome Trust Clinical Research Facility. Controls formed part of a larger study and arrived at 14:00 on Day 1 where a subset (24/41) performed a sub-maximal exercise test at 15:30, all participants were given an energy balanced standardised evening meal (30-35\% fat, 50-55\% carbohydrate, $12-15 \%$ protein) at 18:30. On Day 2 fasting blood samples were taken and a light breakfast provided before ${ }^{1} \mathrm{H}$ MRS at 09:30. Athletes were instructed to refrain from vigorous exercise for at least 24 hours prior to arrival at 08:00 when fasting blood samples were taken before participants consumed a light breakfast, before ${ }^{1} \mathrm{H}$ 
MRS at 09:30 followed by a maximal $\mathrm{VO}_{2 \max }$ exercise test. Lipodystrophic patients also had ${ }^{1} \mathrm{H}$ MRS in the fed state but did not perform an exercise test.

HOMA-IR was calculated as fasting insulin (pmol/l)*fasting glucose $(\mu \mathrm{U} / \mathrm{ml}) / 22.5$. Body composition was assessed by Dual-energy X-ray Absorptiometry (GE Lunar Prodigy encore v12.5 or GE Lunar iDXA encore v16 (athletes).

\section{${ }^{1}$ H Magnetic Resonance Spectroscopy $\left({ }^{1} \mathrm{H}\right.$ MRS)}

${ }^{1} \mathrm{H}$ MRS studies were performed on a Siemens 3T scanner (Erlangen, Germany) using the Point-Resolved Spectroscopy (PRESS) sequence with short echo time of $35 \mathrm{~ms}$. A watersuppressed ${ }^{1} \mathrm{H}$ spectrum was acquired from a voxel of cube length $1.3 \mathrm{~cm}$ positioned to avoid visible fat on $\mathrm{T}_{1}$-weighted images within $\mathrm{TA}$ and $\mathrm{SOL}$, using a $5 \mathrm{~s}$ repetition time and 64 averages (non-water-suppressed spectrum 4 averages). Data were analysed in jMRUI $(19,20)$ and fitted with the AMARES (21) algorithm using identical prior knowledge parameters: Gaussian lineshapes (except water: Lorentzian), soft constraints on EMCL/IMCL $\mathrm{CH}_{2}$ frequencies and linewidths, $\mathrm{CH}_{3}$ resonant frequencies and linewidths determined from known and inferred prior knowledge relative to the $\mathrm{CH}_{2}$ resonance (22), and with all amplitudes estimated. IMCL $\mathrm{CH}_{2}$ and $\mathrm{CH}_{3}$ are quantified relative to the methyl group of creatine plus phosphocreatine at $3.0 \mathrm{ppm}(\mathrm{Cr})$. As this resonance exhibits different lineshape characteristics in the tibialis anterior and soleus muscles (23), comparable quantification between muscles using a nominal concentration of muscle creatine is not valid; instead a scaling factor of $\mathrm{Cr}$ to water signal for each muscle was established from a subset of participants who had nonwater-suppressed datasets, yielding a calculated water signal (water-calc). Absolute composition-independent IMCL concentrations in $\mathrm{mmol} / \mathrm{kg}$ muscle wet weight (ww) were calculated from the compositionally invariant $\mathrm{CH}_{3}$ IMCL resonance, with standard 
115 assumptions regarding muscle water content, and correction for $\mathrm{T}_{2}$ relaxation effects, $\mathrm{J}$

116 coupling and proton density as outlined in the supplementary information (24). The IMCL

117 saturation index $\left(\mathrm{CH}_{2}: \mathrm{CH}_{3}\right)$ was calculated as IMCL $\mathrm{CH}_{2} / \mathrm{CH}_{3}$, and the IMCL saturation index

118 adjusted for quantity $\left(\mathrm{CH}_{2}: \mathrm{CH}_{3 \mathrm{adj}}\right)=\mathrm{CH}_{2}-\left(\mathrm{mCH}_{3}+\mathrm{c}\right)$, where $\mathrm{m}$ and $\mathrm{c}$ are the gradient and

119 intercept of the regression line through the control data points of $\mathrm{CH}_{2} \mathrm{vs} \mathrm{CH}_{3}$. Investigators

120 were blind to the insulin resistance status of the participants during ${ }^{1} \mathrm{H}$ MRS analysis.

\section{Assessment of $\mathrm{VO}_{2 \max }$}

122 Participants underwent continuous incremental exercise testing to $85 \%$ age-predicted

123 maximum heart rate (controls) or volitional exhaustion (athletes) on a treadmill (Trackmaster

124 TMX425, Med-electronics, MD). Oxygen consumption was measured using a spiro-

125 ergometer (Medical Graphics UK Ltd and Breezesuit ${ }^{\circledR}$ Gas exchange software). For the

126 control participants a standard incremental protocol was performed (25), while the athletes

127 undertook a protocol that began with a 10 min warm-up period at each participant's preferred

128 warm-up running speed, following which the test was initiated at $9 \mathrm{~km} / \mathrm{hr}$ and increased

129 steadily $\left(0.74 \mathrm{~km} \cdot \mathrm{hr}^{-1} \cdot \mathrm{min}^{-1}\right)$, with a ramp at 5 minutes (increasing $0.5 \%$ every $15 \mathrm{~s}$ ) until

130 exhaustion or a plateaux in $\mathrm{VO}_{2}$ was apparent. In controls $\mathrm{VO}_{2 \max }$ was calculated by

131 extrapolating the submaximal heart rate $-\mathrm{VO}_{2}$ relationship to age- predicted maximum heart

132 rate (26).

\section{Statistics}

134 All statistics were performed in IBM SPSS Statistics 24 (IBM, Armonk, NY: IBM Corp.)

135 with significance set at $\mathrm{P}<0.05$. Normality was assessed by the Shapiro-Wilk test and non-

136 normally distributed data were log-transformed prior to statistical testing. ANOVA with

137 Games-Howell post hoc analysis was used to compare means between groups, and Pearson's 
138 correlation coefficient for analyzing associations. Due to the non-normality of LN(HOMA-

139 IR), IMCL associations with HOMA-IR were assessed by Spearman's rank correlation

140 coefficient. Data are mean \pm SEM.

\section{$141 \quad$ Results}

\section{Participants}

143 Of the insulin-resistant patients with lipodystrophy 13 had partial forms (8 patients with

144 FPLD2 due to LMNA mutations, 5 patients with FPLD3 due to PPARG mutations), and 3

145 generalized lipodystrophy (GLD, 2 patients with an acquired form - AGLD, and 1 due to 146 mutations in the PCYT1A gene (27)). EMCL was absent in the 2 patients with AGLD (Figure

147 2), but those with partial forms had EMCL such that overall patients' EMCL was similar to 148 both controls and athletes (Table 1). The age- and gender-matched controls had a wide range 149 of BMI $\left(19.6\right.$ - $\left.35.6 \mathrm{~kg} \cdot \mathrm{m}^{-2}\right)$ and HOMA-IR (0.3 - 4.9). As a group, insulin and HOMA-IR

150 were significantly higher in the LD patients and lower in the athletes (Table 1, Figure 3A)

151 compared with controls, as expected. Fat mass and percentage body fat were similar between

152 LD patients and athletes, which were both lower compared to controls (Table 1, Figure 3B).

153 Serum triglycerides were higher whilst high-density lipoprotein (HDL)-cholesterol

154 concentrations were lower in the LD patients (Table 1) compared to either controls or athletes.

\section{${ }^{1} \mathrm{H}$ MRS analysis of intramyocellular TG concentration}

156 In the soleus muscle intramyocellular TG concentrations derived from the IMCL $\mathrm{CH}_{3}$ peak

$157(0.9 \mathrm{ppm})$ (composition-independent IMCL concentrations) were not significantly increased

$158(\mathrm{p}=0.477)$ in the LD patients compared to controls, but were higher compared to the lean athletes $(\mathrm{p}=0.003)$ (Figure 3C). In the more glycolytic tibialis anterior muscle, composition- 
160 independent IMCL concentrations were similar in all three groups (Figure 3D). We also

161 observed linear inverse correlations of $\mathrm{VO}_{2 \max }$ and IMCL concentration in the subset of

162 controls who underwent $\mathrm{VO}_{2 \max }$ testing and athletes together (Figures 3E \& F). Soleus IMCL

163 was significantly lower in the athletes compared to the controls $(p=0.004$, Figure $3 \mathrm{C})$ and

164 this remained significant $(\mathrm{p}=0.025)$ compared to a subset of the controls matched for

165 percentage body fat (body fat $=21.5 \pm 2.3 \%, \mathrm{n}=10$; vs athletes $21.1 \pm 1.8 \%, \mathrm{n}=14$; see

166 supplementary figure (24)).

167 The conventional estimate of IMCL concentration using the $\mathrm{CH}_{2}$ resonance uncorrected for

168 composition, $\mathrm{CH}_{2}$ /water, showed similar trends to the composition-independent estimate

169 using the $\mathrm{CH}_{3}$ peak with the exception that the LD patients' soleus IMCL $\mathrm{CH}_{2}$ was

170 significantly increased compared to controls (Table 1). This could be regarded as an artefact

171 of the effects of compositional differences, which we consider next.

$172 \quad{ }^{1} \mathbf{H}$ MRS analysis of intramyocellular lipid composition

173 IMCL had a significantly higher saturation index $\left(\mathrm{CH}_{2}: \mathrm{CH}_{3}\right)$ in both muscles of the

174 lipodystrophic patients compared to controls (soleus $p=0.008$, tibialis anterior $p=0.024$ ), but

175 not athletes (Figures 4A \& B). In the control group, smaller IMCL pools were associated with

176 a higher saturation index, as shown by the linear regression line (dotted line in Figures $4 \mathrm{C} \&$

177 D) having a gradient $\left(\Delta \mathrm{CH}_{2} / \Delta \mathrm{CH}_{3}\right)<$ the mean $\mathrm{CH}_{2}: \mathrm{CH}_{3}$ (e.g. gradient soleus $=6.7$ vs mean

$178 \mathrm{CH}_{2}: \mathrm{CH}_{3}=8.8$; gradient tibialis anterior $=4.2$ vs mean $\mathrm{CH}_{2}: \mathrm{CH}_{3}=6.0$ ). This phenomenon

179 appeared to be independent of insulin sensitivity in the controls (Table 2: there was no

180 relation of HOMA-IR with IMCL concentration). To generate a pathophysiologically

181 meaningful measure of composition that is independent of IMCL quantity, the vertical $\left(\mathrm{CH}_{2}\right)$

182 deviation from this regression line was measured and taken as a marker of the saturation of 
183 the pool that is adjusted for quantity, which we term the adjusted saturation index

$184\left(\mathrm{CH}_{2}: \mathrm{CH}_{3 a d j}\right)$. This adjusted compositional marker was significantly higher in lipodystrophic 185 patients compared to athletes (soleus $\mathrm{p}=0.001$, tibialis anterior $\mathrm{p}=0.046$ ) and also compared 186 to controls ( 187 conventional statistical significance $(\mathrm{p}=0.06)($ Figures $4 \mathrm{E} \& \mathrm{~F})$.

188 Unlike the uncorrected measure of composition, this adjusted composition also had a 189 significant relation to $\mathrm{VO}_{2 \max }($ Figures $4 \mathrm{G} \& \mathrm{H}$ ) within the control subset alone, athletes alone 190 (soleus), and control and athletes combined (statistics are given in the figure legend), such

191 that fitter individuals had less saturated IMCL for the same absolute quantity of IMCL. $192 \mathrm{VO}_{2 \max }$ significantly correlated with HOMA-IR in the control subset $(\mathrm{r}=-0.59, \mathrm{p}=0.003, \mathrm{n}=$ $19323)$ and in controls and athletes together $(\mathrm{r}=-0.53, \mathrm{p}=0.001, \mathrm{n}=37)$. Table 2 shows 194 relations of IMCL concentration and composition with insulin sensitivity.

195 The saturation index was higher in the soleus muscle compared with the tibialis anterior in all 1963 groups. This was still the case in the two EMCL-deficient AGLD patients (P1 soleus $\mathrm{CH}_{2}: \mathrm{CH}_{3}=9.5$, TA $\mathrm{CH}_{2}: \mathrm{CH}_{3}=6.3 ; \mathrm{P} 2$ soleus $\mathrm{CH}_{2}: \mathrm{CH}_{3}=11.2, \mathrm{TA} \mathrm{CH}_{2}: \mathrm{CH}_{3}=7.1$ )

\section{Discussion}

200 Using a recently validated ${ }^{1} \mathrm{H}$ magnetic resonance spectroscopy method we have compared a 201 compositional saturation index $\left(\mathrm{CH}_{2}: \mathrm{CH}_{3}\right.$ ratio) of intramyocellular lipid in the soleus and 202 tibialis anterior muscles of female insulin-resistant lipodystrophic patients with that of age203 and gender-matched athletes and healthy controls, and shown it to be significantly higher in 204 both muscles compared with controls, but not athletes. The finding that smaller IMCL pools 
in the control group had a relatively higher saturation index than larger pools irrespective of insulin sensitivity could possibly explain why the athletes studied here, who had small IMCL pools, had a statistically similar composition to patients. This observed concentration composition relation seems physiologically plausible given that more unsaturated and shorterchain FA are preferentially mobilized (17). We hypothesize that a person may 'move' along a

210 line such as this while performing daily activities, and that a measurement of deviation from 211 this relationship may therefore be a more sensitive and specific measure of muscle metabolic 212 physiology or pathophysiology. To take this concentration-composition dependence into 213 consideration we adjusted the compositional saturation index for concentration $\left(\mathrm{CH}_{2}: \mathrm{CH}_{3 a d j}\right)$, 214 and this marker was able to distinguish between athletes and lipodystrophic patients in both 215 muscles. The strong inverse relation of $\mathrm{CH}_{2}: \mathrm{CH}_{3 \text { adj }}$ with $\mathrm{VO}_{2}$ max indicates that fitness is 216 associated with relatively lower saturation of IMCL, although overall athletes and controls 217 were not statistically different; this is similar to results from a biopsy study (28) that 218 demonstrated a comparable percentage saturated IMCL in controls and athletes.

219 By our measure of composition-independent IMCL (using the $\mathrm{CH}_{3}$ instead of the uncorrected $220 \mathrm{CH}_{2}$ resonance) we found that the lipodystrophic patients' IMCL concentration was not 221 significantly higher in either muscle compared with age-, gender- and BMI-matched controls, 222 but was raised in the soleus relative to athletes. There are few reports of IMCL in 223 lipodystrophic patients, but our findings are in agreement with Peterson et al. (29) who, in 3 224 patients with generalized lipodystrophy (2 congenital, 1 acquired), found similar soleus IMCL 225 to 6 age-, BMI- and weight-matched controls. Calf IMCL was also lower in a case report of 226 acquired generalized lipodystrophy (30) compared to controls, whilst a study of 4 patients 227 with congenital generalized lipodystrophy suggested that IMCL was higher (31). Using the $228 \mathrm{CH}_{2}$ resonance, as is conventional in previous literature, we found soleus IMCL 'content' to 
be significantly higher in our LD patients compared with controls (Table 1), demonstrating,

230 we argue, the influence of composition on measures of concentration.

\section{The athlete's paradox}

232 We found that the athletes' IMCL was significantly lower (soleus) or similar (tibialis anterior) 233 to controls. Although this appears to contradict well-known literature reports of an athlete's 234 paradox using both biopsy methods $(13,28,32-34)$ and ${ }^{1} \mathrm{H}$ MRS $(35,36)$, this finding is in 235 agreement with literature that reports no such paradox compared to old or young controls 236 (37), obese individuals (38), or in certain fibre types (14). It is known that athletes can have a 237 large depletion-repletion range of IMCL and it is possible that IMCL had not fully recovered 238 since the last training session ( $24-48 \mathrm{hrs}$ prior) as IMCL can still rise significantly after 239 these intervals (39). In fact, our results demonstrate an inverse relation of IMCL content and $240 \mathrm{VO}_{2 \max }$ which is consistent with a study by Boesch et al. (40) where a combination of daily 241 training at $60 \% \mathrm{VO}_{2}$ peak with a low fat $(10-15 \%$ fat) diet depleted IMCL levels in both the

242 vastus lateralis and tibialis anterior muscles to a consistent level that correlated with $\mathrm{VO}_{2}$ peak, 243 suggesting our female elite athletes were nearly 'empty' of IMCL; we did not control for diet 244 in our study.

\section{Relationship of whole-body insulin resistance to IMCL}

246 Within the controls, only the compositional saturation index adjusted for quantity $247\left(\mathrm{CH}_{2}: \mathrm{CH}_{3 \text { adj }}\right)$ in soleus was significantly correlated with whole-body insulin resistance (Table 248 2). The inclusion of insulin-resistant patients increases the statistical significance of this 249 relation and also yields associations with other composition-influenced markers, but not 250 IMCL concentration in either muscle. In our study, the addition of athletes predictively 251 reduced the associations with composition as their pools were small and therefore had a 
tendency for higher saturation index, but relations remain with measures that reflect large

253 saturated pools (i.e. $\mathrm{CH}_{2}: \mathrm{CH}_{3}$ adj and $\mathrm{CH}_{2}$ ). These striking results suggest that the relative

254 composition and not concentration relates to early stage insulin resistance.

\section{Limitations}

256 Unlike previous ${ }^{1} \mathrm{H}$ MRS studies that have conventionally reported IMCL concentrations

257 using the predominant $\mathrm{CH}_{2}$ resonance whilst assuming a notional normal composition, here

258 we have utilized the smaller $\mathrm{CH}_{3}$ resonance which has the advantage of composition-

259 independence and, with comprehensive prior knowledge constraints including line width

260 constraints relative to the $\mathrm{CH}_{2}$ resonance (22), fitted the IMCL $\mathrm{CH}_{3}$ resonance from the

261 overlapping EMCL/IMCL $\mathrm{CH}_{3}$ signals. Due to fibre orientation differences between the

262 soleus and tibialis anterior muscles the EMCL resonances are very slightly systematically

263 shifted between muscle groups. Despite this potential for a systematic difference in the

$264 \mathrm{CH}_{2}: \mathrm{CH}_{3}$ ratio between muscles, this ratio was still higher in the soleus compared to the

265 tibialis anterior muscle in both EMCL-deficient AGLD patients, consistent with findings in

266 our other participants in this study and a previous study (17) suggesting a compositional

267 difference between muscles. Our patients, who mainly had partial forms of lipodystrophy, had

268 overall similar quantities of EMCL to those of our controls and athletes which has helped in

269 reducing potential inter-group influence of this overlapping resonance. This, together with the

270 finding that the IMCL $\mathrm{CH}_{2}: \mathrm{CH}_{3}$ ratio had no relation to either $\mathrm{EMCL} \mathrm{CH}_{2}$ or $\mathrm{CH}_{3}$ suggests a

271 lack of EMCL influence in our datasets; however, it is possible that in other insulin-resistant

272 cohorts large overlapping EMCL resonances may be a confounding factor.

\section{Summary}


274 Use of our recently validated and potentially widely applicable ${ }^{1} \mathrm{H}$ MRS approach to 275 determine both the IMCL composition and concentration independent of composition within 276 the soleus and tibialis anterior muscles of female individuals covering a wide range of insulin 277 sensitivities has revealed that the IMCL composition saturation index adjusted for quantity is 278 more strongly associated with whole-body insulin resistance than IMCL concentration alone. 279 Differences in associations of insulin resistance with IMCL concentration when using the $\mathrm{CH}_{3}$ 280 and conventional $\mathrm{CH}_{2}$ peaks for quantification highlights the need for awareness of the 281 potential influence of composition on previously-reported ${ }^{1} \mathrm{H}$ MRS measures of 282 concentration.

283 Our finding of a strong relationship between of $\mathrm{VO}_{2 \max }$ and relatively unsaturated IMCL pools 284 in controls and athletes points to a role of exercise in decreasing the amount of saturated fat 285 within the IMCL store, and suggests that the composition would be able to distinguish 286 athletes from insulin-resistant patients in cases of the athlete's paradox. The association of 287 insulin resistance with accumulation of saturated IMCL, even within a healthy control 288 population, could suggest an early involvement in its pathogenesis and provide a reason why 289 combined exercise and diet are effective therapeutic options in the early stages of insulin 290 resistance.

\section{Acknowledgments}

293 We thank all the participants, staff at both the NIHR Cambridge Clinical Research Facility 294 and the Wolfson Brain Imaging Centre (WBIC). We acknowledge the NIHR Core 295 Biochemistry Assay Laboratory, Cambridge Biomedical Research Centre, UK, for providing 
296 the insulin analysis. We thank Wiktor Olszowy (WBIC) for statistical advice. This research

297 was supported by grants from the Clinical Research Infrastructure Grant, UK NIHR

298 Cambridge Biomedical Research Centre, and the UK Medical Research Council Centre for

299 Obesity and Related Metabolic Diseases. DBS is supported by the Wellcome Trust (107064)

300 and AS by the NIHR via an award to the NIHR Cambridge Clinical Research Facility. The

301 views expressed in this manuscript are those of the authors and not necessarily those of the

302 NHS, the NIHR or the Department of Health and Social Care. 


\section{References}

304

305

306

307

308

309

1. Schick F, Eismann B, Jung W-I, Bongers H, Bunse M, Lutz O. Comparison of localized proton NMR signals of skeletal muscle and fat tissue in vivo: two lipid compartments in muscle tissue. Magn. Reson. Med. 1993;29(2):158-167.

2. Boesch C, Slotboom J, Hoppeler H, Kreis R. In vivo determination of intramyocellular lipids in human muscle by means of localized ${ }^{1} \mathrm{H}-\mathrm{MR}$-spectroscopy. Magn. Reson. Med. 1997;37(4):484-493.

3. Perseghin G, Scifo P, De Cobelli F, Pagliato E, Battezzati A, Arcelloni C, Vanzulli A, Testolin G, Pozza G, Del Maschio A, Luzi L. Intramyocellular triglyceride content is a determinant of in vivo insulin resistance in humans: a ${ }^{1} \mathrm{H}-{ }^{13} \mathrm{C}$ nuclear magnetic resonance spectroscopy assessment in offspring of type 2 diabetic parents. Diabetes 1999;48(8):1600-6.

4. Jacob S, Machann J, Rett K, Brechtel K, Volk A, Renn W, Maerker E, Matthaei S, Schick F, Claussen CD, Häring HU. Association of increased intramyocellular lipid content with insulin resistance in lean nondiabetic offspring of type 2 diabetic subjects. Diabetes 1999;48(5):1113-9.

5. Krssak M, Falk Petersen K, Dresner A, DiPietro L, Vogel SM, Rothman DL, Shulman GI, Roden M. Intramyocellular lipid concentrations are correlated with insulin sensitivity in humans: a ${ }^{1} \mathrm{H}$ NMR spectroscopy study. Diabetologia 1999;42(1):113-116.

6. Shulman GI, Rothman DL, Jue T, Stein P, DeFronzo RA, Shulman RG.

Quantitation of muscle glycogen synthesis in normal subjects and subjects with noninsulin-dependent diabetes by ${ }^{13} \mathrm{C}$ nuclear magnetic resonance spectroscopy. N. Engl. J. Med. 1990;322(4):223-228.

7. Petersen KF, Shulman GI. Pathogenesis of skeletal muscle insulin resistance in type 2 diabetes mellitus. Am. J. Cardiol. 2002;90(5):11-18.

8. Savage DB, Petersen KF, Shulman GI. Mechanisms of insulin resistance in humans and possible links with inflammation. Hypertens. (Dallas, Tex. 1979) 2005;45(5):82833.

9. Sinha R, Dufour S, Petersen KF, LeBon V, Enoksson S, Ma Y-Z, Savoye M, Rothman DL, Shulman GI, Caprio S. Assessment of skeletal muscle triglyceride content by ${ }^{1} \mathrm{H}$ nuclear magnetic resonance spectroscopy in lean and obese adolescents: relationships to insulin sensitivity, total body fat, and central adiposity. Diabetes 2002;51(4):1022-7.

10. Phillips DIW, Caddy S, Ilic V, Fielding BA, Frayn KN, Borthwick AC, Taylor R. Intramuscular triglyceride and muscle insulin sensitivity: Evidence for a relationship in 
nondiabetic subjects. Metabolism 1996;45(8):947-950.

11. Pan DA, Lillioja S, Kriketos AD, Milner MR, Baur LA, Bogardus C, Jenkins AB, Storlien LH. Skeletal muscle triglyceride levels are inversely related to insulin action. Diabetes 1997;46(6):983-8.

12. Forouhi NG, Jenkinson G, Thomas EL, Mullick S, Mierisova S, Bhonsle U, McKeigue PM, Bell JD. Relation of triglyceride stores in skeletal muscle cells to central obesity and insulin sensitivity in European and South Asian men. Diabetologia 1999;42(8):932-935.

13. Goodpaster BH, He J, Watkins S, Kelley DE. Skeletal muscle lipid content and insulin resistance: evidence for a paradox in endurance-trained athletes. $J$ Clin Endocrinol Metab. 2001;86(12):5755-5816.

14. van Loon LJC, Koopman R, Manders R, van der Weegen W, van Kranenburg GP, Keizer HA. Intramyocellular lipid content in type 2 diabetes patients compared with overweight sedentary men and highly trained endurance athletes. Am. J. Physiol. Metab. 2004;287(3):E558-E565.

15. Hernández EÁ, Kahl S, Seelig A, Begovatz P, Irmler M, Kupriyanova Y, Nowotny B, Nowotny P, Herder C, Barosa C, Carvalho F, Rozman J, Neschen S, Jones JG, Beckers J, de Angelis MH, Roden M. Acute dietary fat intake initiates alterations in energy metabolism and insulin resistance. J. Clin. Invest. 2017;127(2):695-708.

16. Luukkonen PK, Sädevirta S, Zhou Y, Kayser B, Ali A, Ahonen L, Lallukka S, Pelloux V, Gaggini M, Jian C, Hakkarainen A, Lundbom N, Gylling H, Salonen A, Orešič M, Hyötyläinen T, Orho-Melander M, Rissanen A, Gastaldelli A, Clément K, Hodson L, Yki-Järvinen H. Saturated fat is more metabolically harmful for the human liver than unsaturated fat or simple sugars. Diabetes Care 2018:dc180071.

17. Thankamony A, Kemp GJ, Koulman A, Bokii V, Savage DB, Boesch C, Hodson L, Dunger DB, Sleigh A. Compositional marker in vivo reveals intramyocellular lipid turnover during fasting-induced lipolysis. Sci. Rep. 2018;8(1):2750.

18. Sleigh A, Stears A, Thackray K, Watson L, Gambineri A, Nag S, Campi VI, Schoenmakers N, Brage S, Carpenter TA, Murgatroyd PR, O'Rahilly S, Kemp GJ, Savage DB. Mitochondrial oxidative phosphorylation is impaired in patients with congenital lipodystrophy. J. Clin. Endocrinol. Metab. 2012;97(3):E438-E442.

19. Naressi A, Couturier C, Devos JM, Janssen M, Mangeat C, de Beer R, GraveronDemilly D. Java-based graphical user interface for the MRUI quantitation package. Magma Magn. Reson. Mater. Physics, Biol. Med. 2001;12(2-3):141-152.

20. Stefan D, Cesare F Di, Andrasescu A, Popa E, Lazariev A, Vescovo E, Strbak O, 
Williams S, Starcuk Z, Cabanas M, van Ormondt D, Graveron-Demilly D. Quantitation of magnetic resonance spectroscopy signals: the jMRUI software package. Meas. Sci. Technol. 2009;20(10):104035.

21. Vanhamme L, Van Den Boogaart A, Van Huffel S. Improved method for accurate and efficient quantification of MRS data with use of prior knowledge. J. Magn. Reson. 1997;129:35-43.

22. Boesch C, Machann J, Vermathen P, Schick F. Role of proton MR for the study of muscle lipid metabolism. NMR Biomed. 2006;19(7):968-988.

23. Vermathen $\mathbf{P}$, Boesch $\mathbf{C}$, Kreis R. Mapping fiber orientation in human muscle by proton MR spectroscopic imaging. Magn. Reson. Med. 2003;49(3):424-432.

24. Savage DB, Watson L, Carr, K, Adams C, Brage S, Chatterjee KK, Hodson L, Boesch C, Kemp GJ, Sleigh A . Magnetic resonance spectroscopy analysis of intramyocellular lipid composition in lipodystrophic patients and athletes. bioRxiv. Suppl.:Deposited 1 August 2018. http://www.biorxiv.org.

25. Brage S, Brage N, Ekelund U, Luan J, Franks PW, Froberg K, Wareham NJ. Effect of combined movement and heart rate monitor placement on physical activity estimates during treadmill locomotion and free-living. Eur. J. Appl. Physiol. 2006;96(5):517-524.

26. Tanaka H, Monahan KD, Seals DR. Age-predicted maximal heart rate revisited. $J$. Am. Coll. Cardiol. 2001;37(1):153-156.

27. Payne F, Lim K, Girousse A, Brown RJ, Kory N, Robbins A, Xue Y, Sleigh A, Cochran E, Adams C, Dev Borman A, Russel-Jones D, Gorden P, Semple RK, Saudek V, O'Rahilly S, Walther TC, Barroso I, Savage DB. Mutations disrupting the Kennedy phosphatidylcholine pathway in humans with congenital lipodystrophy and fatty liver disease. Proc. Natl. Acad. Sci. U. S. A. 2014;111(24):8901-6.

28. Bergman BC, Perreault L, Hunerdosse DM, Koehler MC, Samek AM, Eckel RH. Increased intramuscular lipid synthesis and low saturation relate to insulin sensitivity in endurance-trained athletes. J. Appl. Physiol. 2010;108(5):1134-1141.

29. Petersen KF, Oral EA, Dufour S, Befroy D, Ariyan C, Yu C, Cline GW, DePaoli AM, Taylor SI, Gorden P, Shulman GI. Leptin reverses insulin resistance and hepatic steatosis in patients with severe lipodystrophy. J. Clin. Invest. 2002;109(10):1345-50.

30. Brechtel K, Jacob S, Machann J, Hauer B, Nielsen M, Meissner HP, Matthaei S, Haering HU, Claussen CD, Schick F. Acquired generalized lipoatrophy (AGL): Highly selective MR lipid imaging and localized ${ }^{1} \mathrm{H}-\mathrm{MRS}$. J. Magn. Reson. Imaging 2000;12(2):306-310. 
31. Szczepaniak LS, Babcock EE, Schick F, Dobbins RL, Garg A, Burns DK, Denis Mcgarry J, Stein DT, Denis McGarry J. Measurement of intracellular triglyceride stores by ${ }^{1} \mathrm{H}$ spectroscopy: validation in vivo. Am. J. Physiol. - Endocrinol. Metab. 1999;276:E977-E989.

32. Gemmink A, Daemen S, Brouwers B, Huntjens PR, Schaart G, Moonen-Kornips E, Jörgensen J, Hoeks J, Schrauwen P, Hesselink MKC. Dissociation of intramyocellular lipid storage and insulin resistance in trained athletes and type 2 diabetes patients; involvement of perilipin 5? J. Physiol. 2018;596(5):857-868.

33. Amati F, Dubé JJ, Alvarez-Carnero E, Edreira MM, Chomentowski P, Coen PM, Switzer GE, Bickel PE, Stefanovic-Racic M, Toledo FGS, Goodpaster BH. Skeletal muscle triglycerides, diacylglycerols, and ceramides in insulin resistance: another paradox in endurance-trained athletes? Diabetes 2011;60(10):2588-97.

34. Russell AP, Gastaldi G, Bobbioni-Harsch E, Arboit P, Gobelet C, Dériaz O, Golay A, Witztum JL, Giacobino J-P. Lipid peroxidation in skeletal muscle of obese as compared to endurance-trained humans: a case of good vs. bad lipids? FEBS Lett. 2003;551(1-3):104-106.

35. Décombaz J, Schmitt B, Ith M, Decarli B, Diem P, Kreis R, Hoppeler H, Boesch C. Postexercise fat intake repletes intramyocellular lipids but no faster in trained than in sedentary subjects. Am. J. Physiol. Integr. Comp. Physiol. 2001;281(3):R760-R769.

36. Klepochová R, Valkovič L, Hochwartner T, Triska C, Bachl N, Tschan H, Trattnig S, Krebs M, Krššák M. Differences in muscle metabolism between triathletes and normally active volunteers investigated using multinuclear magnetic resonance spectroscopy at 7T. Front. Physiol. 2018;9:300.

37. Bruce CR, Anderson MJ, Carey AL, Newman DG, Bonen A, Kriketos AD, Cooney GJ, Hawley JA. Muscle oxidative capacity is a better predictor of insulin sensitivity than lipid status. J. Clin. Endocrinol. Metab. 2003;88(11):5444-5451.

38. Bergman BC, Perreault L, Strauss A, Bacon S, Kerege A, Harrison K, Brozinick JT, Hunerdosse DM, Playdon MC, Holmes W, Bui HH, Sanders P, Siddall P, Wei T, Thomas MK, Kuo MS, Eckel RH. Intramuscular triglyceride synthesis: importance in muscle lipid partitioning in humans. Am. J. Physiol. Metab. 2018;314(2):E152-E164.

39. Howald H, Boesch C, Kreis R, Matter S, Billeter R, Essen-Gustavsson B, Hoppeler H. Content of intramyocellular lipids derived by electron microscopy, biochemical assays, and ${ }^{1}$ H-MR spectroscopy. J. Appl. Physiol. 2002;92(6):2264-2272.

40. Ith M, Huber PM, Egger A, Schmid J-P, Kreis R, Christ E, Boesch C. Standardized protocol for a depletion of intramyocellular lipids (IMCL). NMR Biomed. 2010;23(5):532-538. 


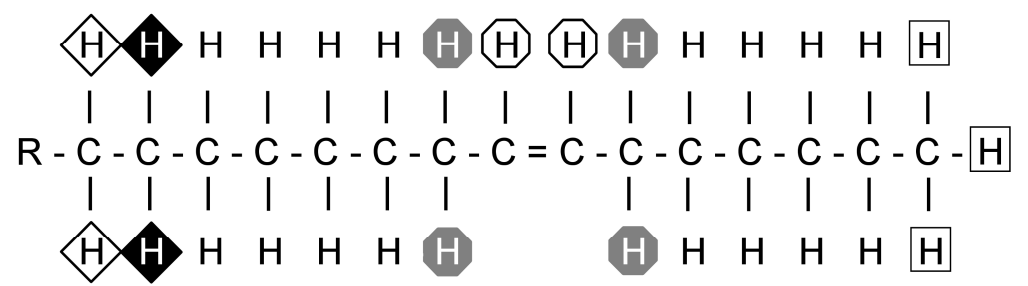

Figure 1. The ratio of $\mathrm{CH}_{2}: \mathrm{CH}_{3}$ is influenced primarily by the degree of saturation of the

fatty acids within triglyceride. This figure shows the principle of the $\mathrm{CH}_{2}: \mathrm{CH}_{3}$ ratio as a

$\mathrm{CH}_{2}$ but also to the alteration in the chemical environment of the neighbouring $\mathrm{CH}_{2}$. For FA 
474

475

476

477

478

479

480

481

482

483

484

485

486

487

488

489

490

491

492

493

494

495

496

497

498
AGLD

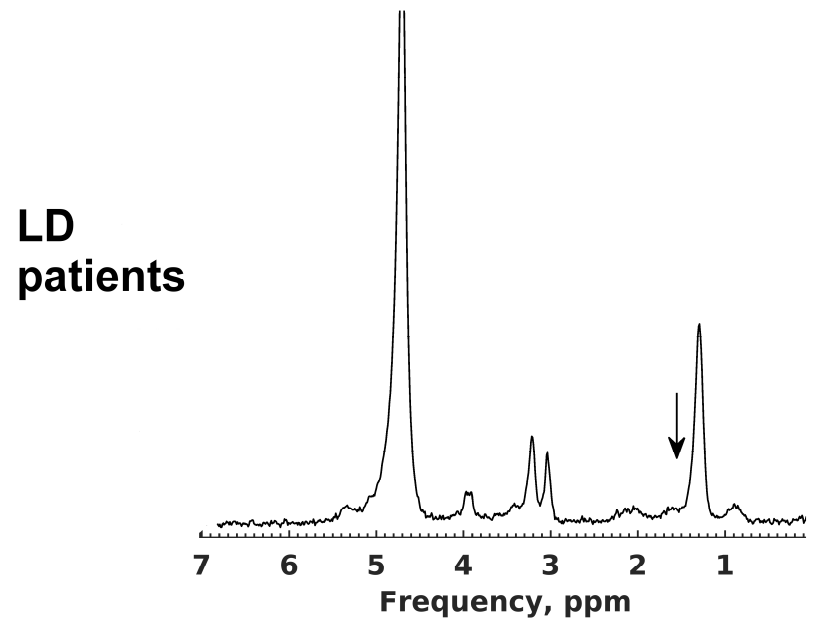

Soleus

Athlete

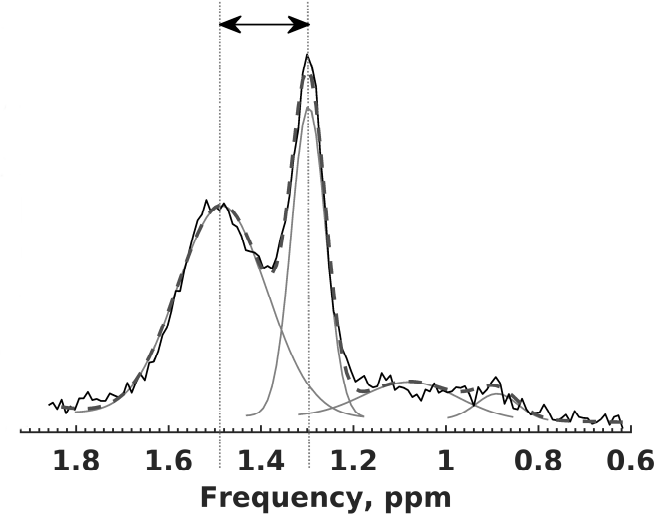

FPLD3

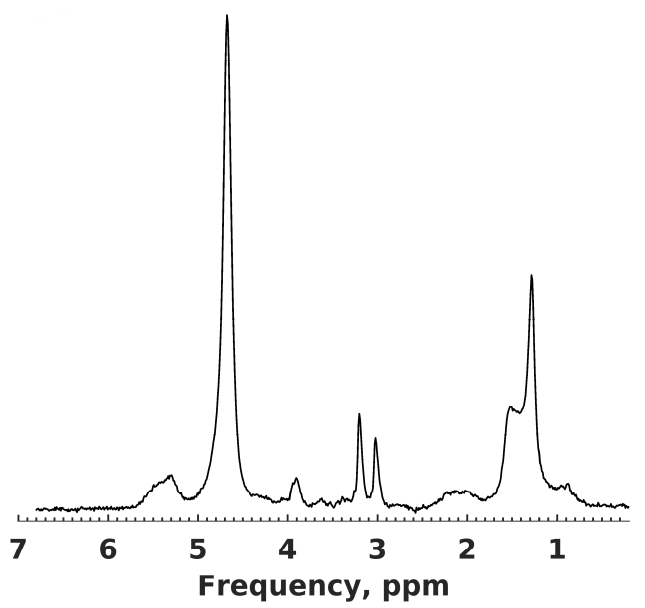

Tibialis anterior

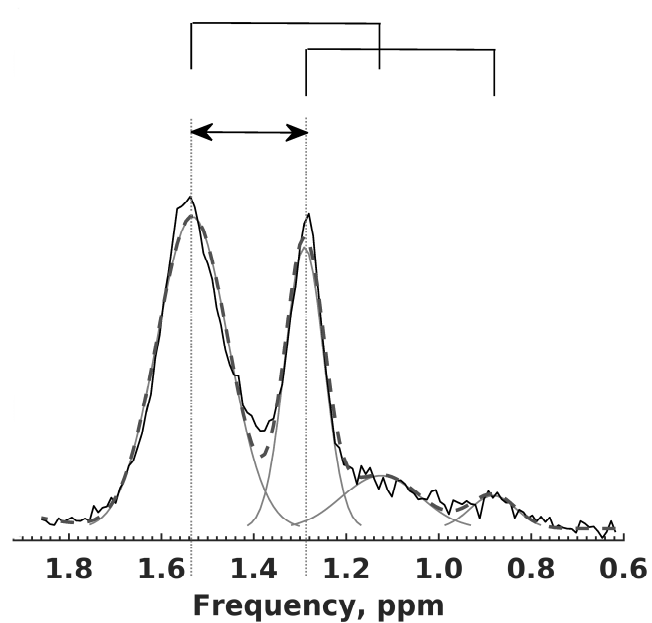

Figure 2. Representative ${ }^{1} \mathrm{H}$ MRS spectra from lipodystrophic (LD) patients and an athlete. Water-suppressed spectra from the soleus muscle of a patient with acquired generalised lipodystrophy (AGLD, upper left) and familial partial lipodystrophy (FPLD3, upper right); the absence of extramyocellular lipid (EMCL) in AGLD is highlighted by the vertical arrow. Spectra from an athlete's soleus (lower left) and tibialis anterior (lower right) muscles illustrating the raw data (solid black) and overall fit (grey dashed) and individual fit components (solid grey) in the frequency range that contains the $\mathrm{EMCL} \mathrm{CH}_{2}(\sim 1.5 \mathrm{ppm})$, $\mathrm{CH}_{3}(\sim 1.1 \mathrm{ppm})$ and IMCL $\mathrm{CH}_{2}(1.3 \mathrm{ppm})$ and $\mathrm{CH}_{3}(0.9 \mathrm{ppm})$ resonances. This volunteer had the lowest soleus IMCL concentration of all participants $(2.0 \mathrm{mmol} / \mathrm{kg} \mathrm{ww})$. The horizontal 
arrows highlights that the EMCL resonances are systematically shifted very slightly upfield in

500 the soleus muscle compared with the tibialis anterior due to fibre orientation effects. $\mathrm{The}^{\mathrm{CH}_{3}}$

501 resonant frequencies are linked to the $\mathrm{CH}_{2}$ frequencies (solid bridge lines above spectra) and

502 are also shifted. The fitting procedure fixes the relative $\mathrm{CH}_{2}$ to $\mathrm{CH}_{3}$ frequency shift for both

503 EMCL and IMCL, and also fixes the $\mathrm{CH}_{3}$ linewidth relative to the corresponding $\mathrm{CH}_{2}$, but

504 permits soft constraints on the EMCL frequencies.

505

506

507

508

509

510

511

512

513

514

515

516

517

518

519

520

521

522

523 
524

525

526

527

528

530

535

C

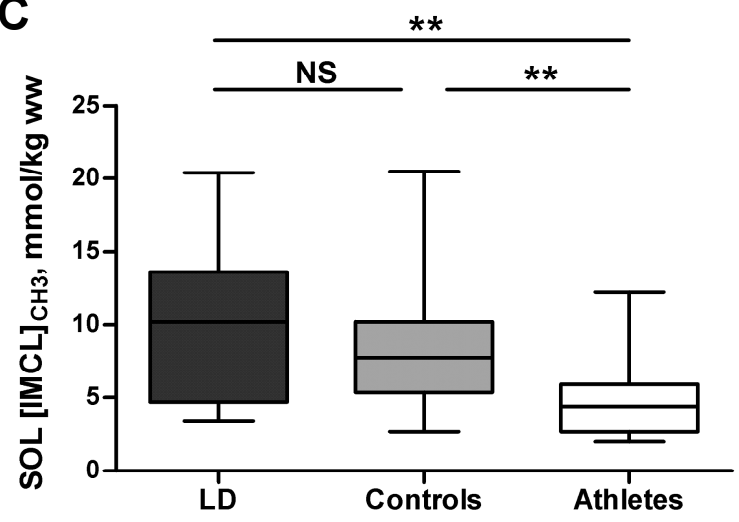

E

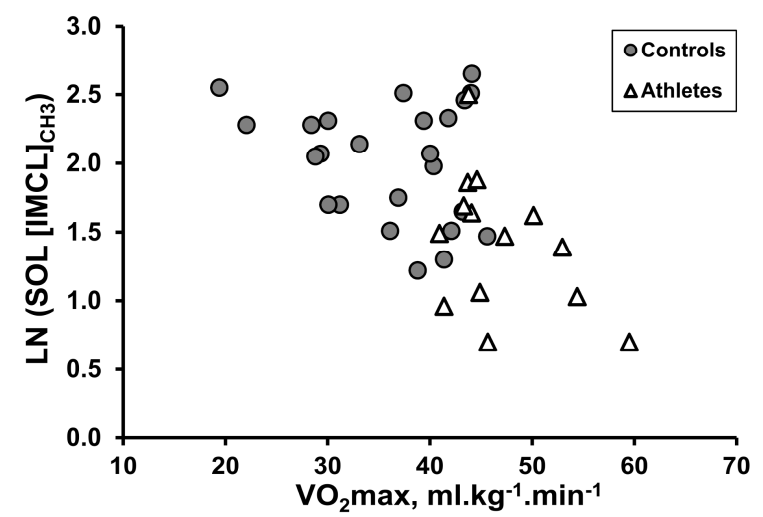

B

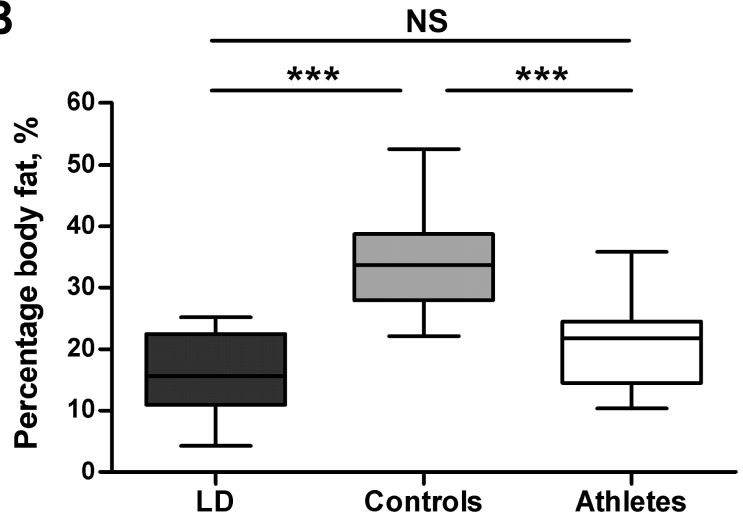

D

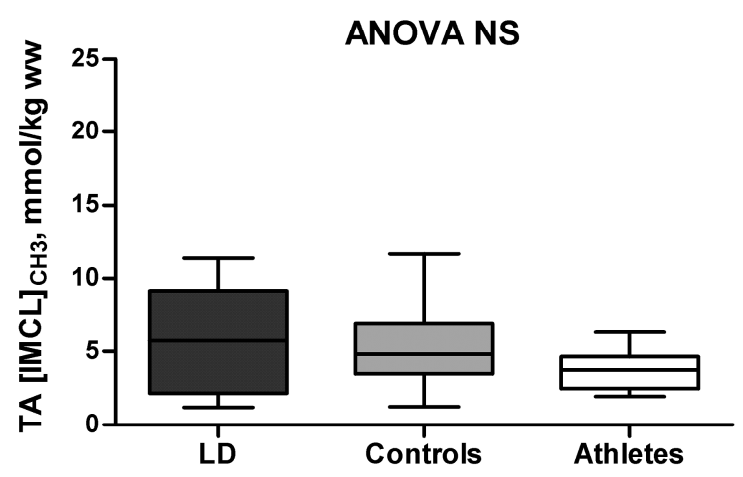

F

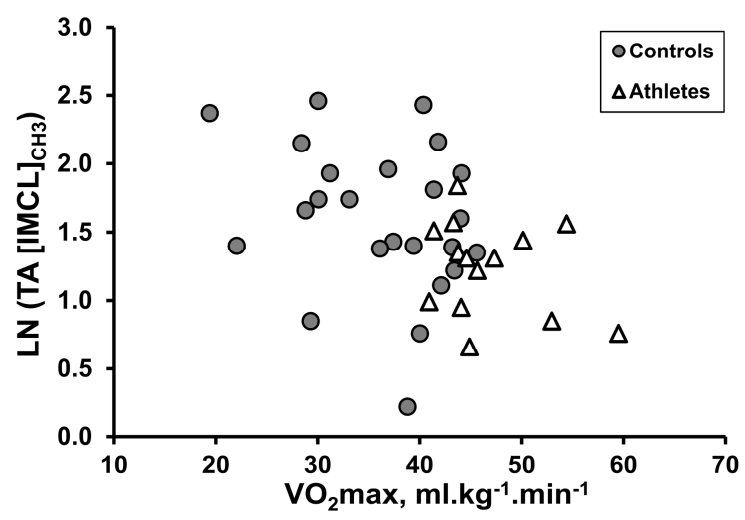

544 Figure 3. Participant characteristics and composition-independent concentrations of

545 intramyocellular lipid in lipodystrophic patients (black), controls (grey), and athletes

546 (white). (A-D) Box and whisker plots showing (A) Whole-body insulin sensitivity assessed

547 by HOMA-IR, (B) Whole-body percentage fat assessed by Dual-Energy X-ray

548 Absorptiometry, and (C, D) Soleus (SOL), tibialis anterior (TA) composition-independent 
549 IMCL concentration assessed from the ${ }^{1} \mathrm{H}$ MRS of methyl protons. The relationship of soleus,

550 tibialis anterior composition-independent IMCL concentration with $\mathrm{VO}_{2 \max }$ in a subset of

551 participants who underwent $\mathrm{VO}_{2 \max }$ testing (controls: grey circles, $\mathrm{n}=24$; athletes: white

552 triangles, $\mathrm{n}=14)$ is shown in $(\mathrm{E}, \mathrm{F})$. This was only significant when controls and athletes were

553 combined, soleus $(\mathrm{r}=-0.52, \mathrm{p}=0.001)$ and tibialis anterior $(\mathrm{r}=-0.42, \mathrm{p}=0.009) .{ }^{*} \mathrm{p}<0.05$,

$554 * * \mathrm{p}<0.01, * * * \mathrm{p}<0.001$. (A-D) tested by ANOVA and Games-Howell post hoc analysis, (E-

555 F) by Pearson's correlation coefficient.

556

557

558

559

560

561

562

563

564

565

566

567

568

569

570

571

572

573 

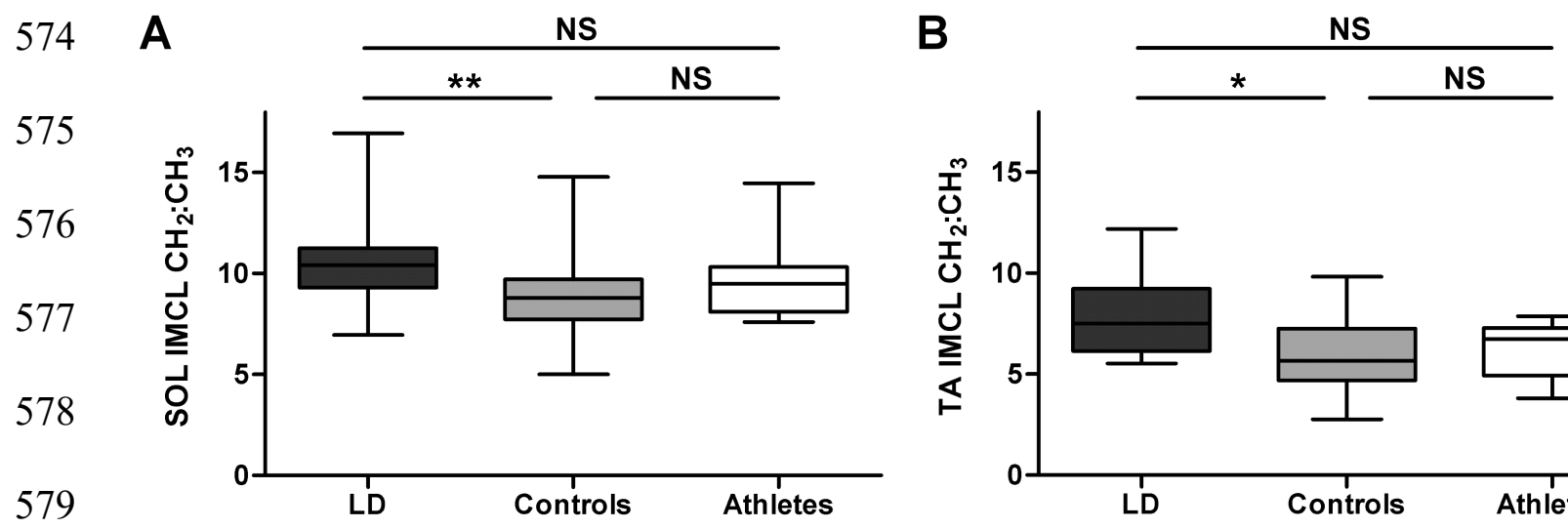

580 C
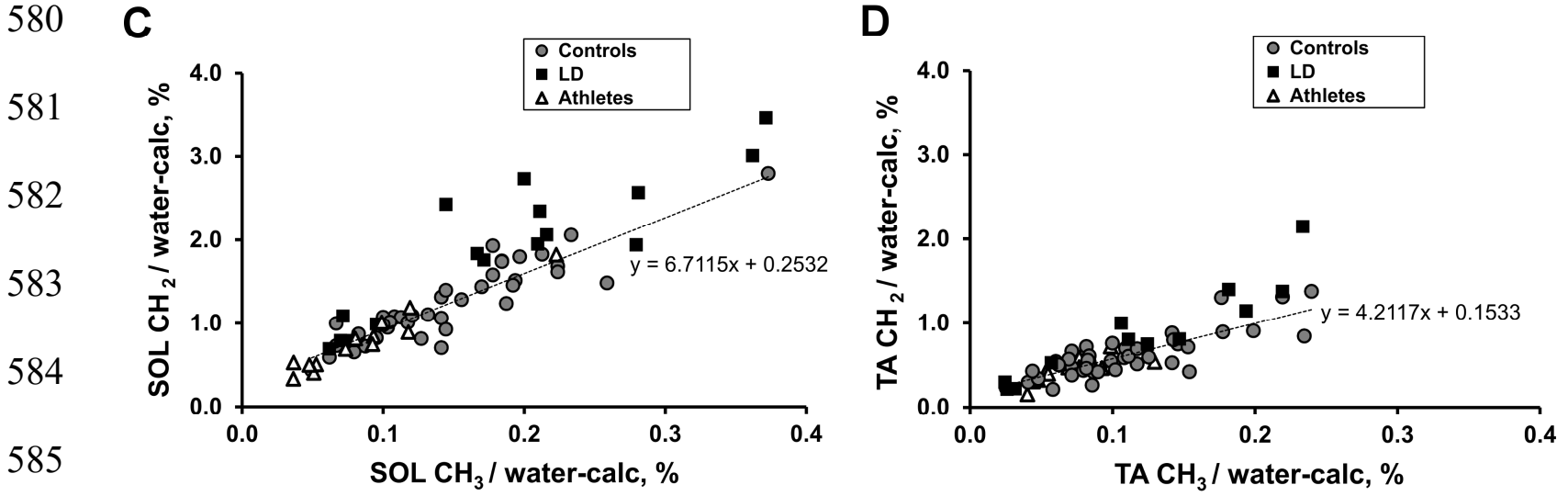

586

E

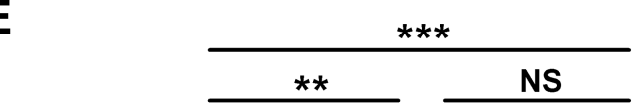

587
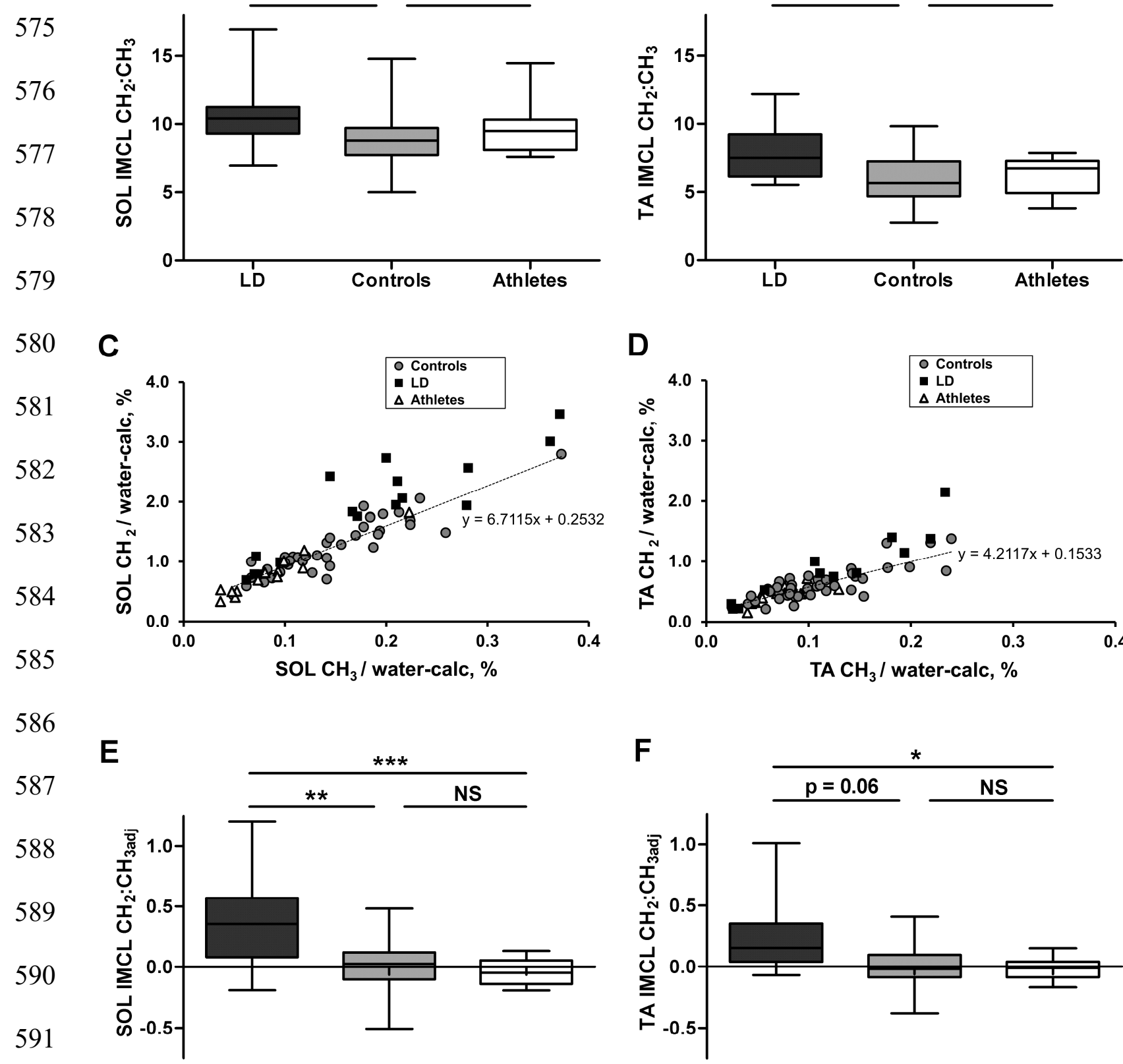

LD

Controls

Athletes

$\mathbf{F}$
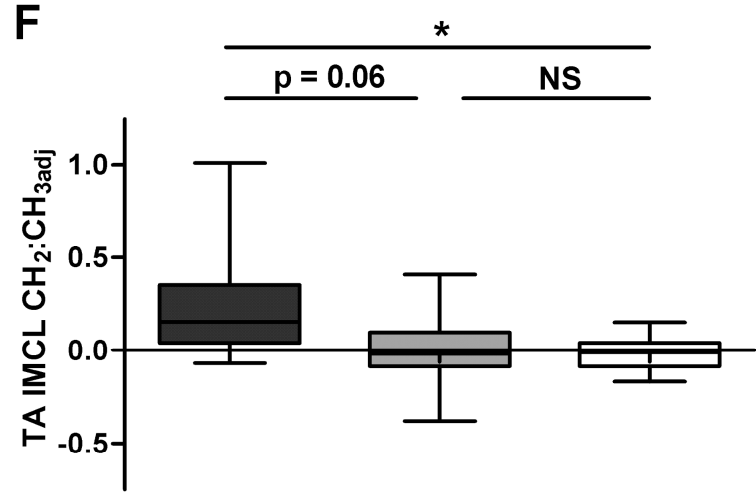

LD

Controls Athletes

593

G

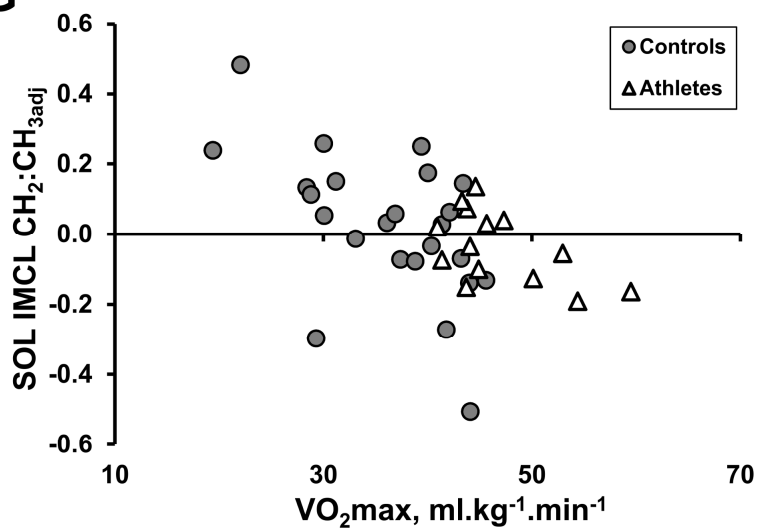

$\mathrm{H}$

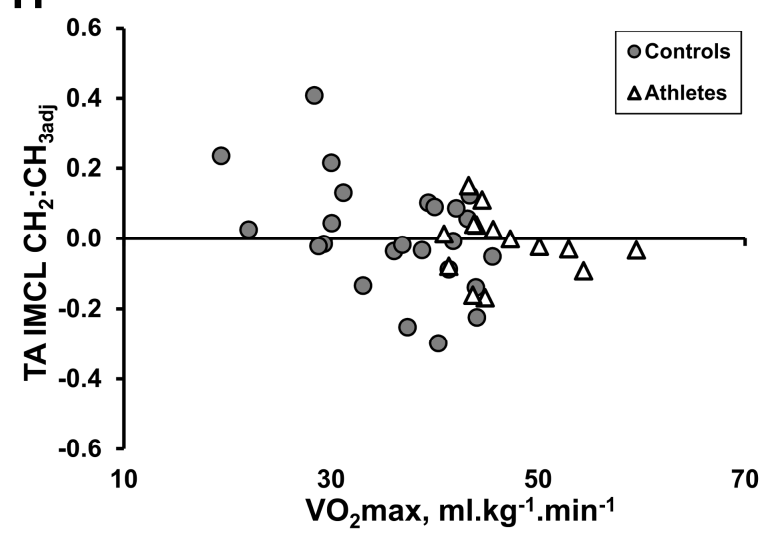


Figure 4. ${ }^{1} \mathrm{H}$ MRS measures of IMCL composition in lipodystrophic patients (black), controls (grey), and athletes (white). (A, B) Box and whisker plots of soleus (SOL) and

601 tibialis anterior (TA) IMCL compositional saturation index $\left(\mathrm{CH}_{2}: \mathrm{CH}_{3}\right.$ ratio). $(\mathrm{C}$, D) Soleus, 602 tibialis anterior IMCL $\mathrm{CH}_{2}$ and $\mathrm{CH}_{3}$ components. The values are expressed relative to the 603 calculated water signal (water-calc), as described in 'Methods'. The dotted line represents the 604 linear regression line of the control data points. (E, F) Box and whisker plots of soleus and 605 tibialis anterior IMCL compositional saturation index adjusted for quantity. $(\mathrm{G}, \mathrm{H})$ Relation of 606 soleus, tibialis anterior IMCL compositional adjusted saturation index with $\mathrm{VO}_{2 \max }$ in the 607 subset of participants who underwent $\mathrm{VO}_{2 \max }$ testing (controls: grey circles, $\mathrm{n}=24$; athletes: 608 white triangles, $\mathrm{n}=14)$. Controls alone, significant correlation in the soleus $(\mathrm{r}=-0.546, \mathrm{p}=$ 609 0.006) and tibialis anterior $(\mathrm{r}=-0.453, \mathrm{p}=0.026)$, athletes alone in the soleus $(\mathrm{r}=-0.558, \mathrm{p}=$ 610 0.038), and with controls and athletes combined in soleus $(\mathrm{r}=-0.520, \mathrm{p}=0.001)$ and tibialis 611 anterior $(\mathrm{r}=-0.362, \mathrm{p}=0.025){ }^{*} \mathrm{p}<0.05, * * \mathrm{p}<0.01, * * * \mathrm{p}<0.001$. (A-B) and (E-F) tested by 612 ANOVA and Games-Howell post hoc analysis, (G-H) by Pearson's correlation coefficient. 
Table 1. Characteristics of the participants, and 'conventional' muscle lipid estimates

\begin{tabular}{|c|c|c|c|c|c|c|c|}
\hline & $\begin{array}{c}\text { Female } \\
\text { LD } \\
n=16\end{array}$ & $\begin{array}{c}\text { Female } \\
\text { controls } \\
n=41\end{array}$ & $\begin{array}{c}\text { Female } \\
\text { athletes } \\
n=14\end{array}$ & $\begin{array}{l}\text { P value } \\
\text { ANOVA }\end{array}$ & $\begin{array}{l}\text { P value } \\
\text { LD- } \\
\text { controls }\end{array}$ & $\begin{array}{l}\text { P value } \\
\text { LD- } \\
\text { athletes }\end{array}$ & $\begin{array}{l}\text { P value } \\
\text { controls } \\
\text {-athletes }\end{array}$ \\
\hline Age, yr & $38.9 \pm 3.9$ & $35.5 \pm 2.0$ & $36.5 \pm 2.9$ & 0.694 & & & \\
\hline BMI, kg.m ${ }^{-2}$ & $24.2 \pm 0.7$ & $24.4 \pm 0.6$ & $20.3 \pm 0.6$ & $<0.001$ & 0.999 & 0.001 & $<0.001$ \\
\hline Mass, kg & $66.1 \pm 2.8$ & $65.2 \pm 2.3$ & $54.6 \pm 1.3$ & 0.013 & 0.916 & 0.006 & 0.001 \\
\hline Fat mass, $\mathrm{kg}$ & $10.6 \pm 1.4$ & $23.1 \pm 1.6$ & $11.6 \pm 1.1$ & $<0.001$ & 0.001 & 0.631 & $<0.001$ \\
\hline FFM, kg & $55.4 \pm 1.7$ & $42.1 \pm 0.9$ & $43.0 \pm 1.2$ & $<0.001$ & $<0.001$ & $<0.001$ & 0.705 \\
\hline $\begin{array}{l}\text { Triglyceride, } \\
\mathrm{mmol} / \mathrm{l}\end{array}$ & $3.54 \pm 0.67$ & $0.92 \pm 0.07^{\mathrm{a}}$ & $0.84 \pm 0.08$ & $<0.001$ & $<0.001$ & $<0.001$ & 0.920 \\
\hline $\begin{array}{l}\text { HDL-cholesterol, } \\
\mathrm{mmol} / 1\end{array}$ & $0.97 \pm 0.71$ & $1.64 \pm 0.06^{\mathrm{a}}$ & $2.20 \pm 0.12$ & $<0.001$ & $<0.001$ & $<0.001$ & 0.001 \\
\hline Glucose, $\mathrm{mmol} / \mathrm{l}$ & $6.00 \pm 0.58$ & $4.56 \pm 0.06^{\mathrm{a}}$ & $4.46 \pm 0.13$ & $<0.001$ & 0.063 & 0.002 & 0.764 \\
\hline Insulin, pmol/1 & $145.6 \pm 22.0$ & $38.6 \pm 4.2^{\mathrm{a}}$ & $22.6 \pm 4.7$ & $<0.001$ & $<0.001$ & $<0.001$ & 0.025 \\
\hline $\mathrm{HbA} 1_{c}, \mathrm{mmol} / \mathrm{mol}$ & $48.3 \pm 4.2^{b}$ & ND & $34.9 \pm 0.7$ & ND & & 0.008 & \\
\hline $\begin{array}{l}\mathrm{VO}_{2 \max }, \mathrm{ml} \cdot \mathrm{kg}^{-} \\
{ }^{1} \cdot \mathrm{min}^{-1}\end{array}$ & ND & $36.1 \pm 1.5^{\mathrm{c}}$ & $46.9 \pm 1.4$ & ND & & & $<0.001$ \\
\hline \multicolumn{8}{|c|}{ Conventional IMCL, EMCL, expressed as $\mathrm{CH}_{2} /$ water-calc in units of \% } \\
\hline SOL IMCL & $1.90 \pm 0.21$ & $1.22 \pm 0.07$ & $0.79 \pm 0.10$ & $<\mathbf{0 . 0 0 1}$ & 0.027 & $<0.001$ & 0.007 \\
\hline TA IMCL & $0.89 \pm 0.16^{\mathrm{d}}$ & $0.61 \pm 0.04$ & $0.45 \pm 0.04$ & 0.035 & 0.562 & 0.115 & 0.078 \\
\hline SOL EMCL & $2.05 \pm 0.34$ & $2.22 \pm 0.19$ & $1.81 \pm 0.20$ & 0.493 & & & \\
\hline TA EMCL & $1.43 \pm 0.28^{\mathrm{d}}$ & $2.30 \pm 0.19$ & $1.24 \pm 0.15$ & 0.002 & 0.163 & 0.785 & 0.005 \\
\hline
\end{tabular}

618

619

620

621

622

623

624

625

626

627

628

629

630

631

632

633

634

635

636

637

638

639

640

Non-normally distributed variables were log-transformed prior to performing ANOVA and Games-Howell post hoc analysis; bold P values are statistically significant. Data presented are mean $\pm \mathrm{SEM}$. To convert insulin $\mathrm{pmol} / 1$ to $\mu \mathrm{U} / \mathrm{ml}$ divide by 6.945 . FFM, fat free mass; ND, not done; IMCL, intramyocellular lipid; EMCL, extramyocellular lipid; SOL, soleus; TA, tibialis anterior; $\mathrm{CH}_{2}$, methylene protons resonating at $1.3 \mathrm{ppm}$ quantified as a percentage of the uncorrected calculated water resonance.

${ }^{\mathrm{a}} \mathrm{n}=38,{ }^{\mathrm{b}} \mathrm{n}=13,{ }^{\mathrm{c}} \mathrm{n}=24,{ }^{\mathrm{d}} \mathrm{n}=12$. 
641

642

643

644

IMCL measure

\section{HOMA-IR}

$\begin{array}{ccc}\text { Controls } & \text { Controls } & \text { Controls, LD } \\ & \text { and LD } & \text { and athletes } \\ \mathrm{n}=38 & \mathrm{n}=54^{\mathrm{a}} & \mathrm{n}=68^{\mathrm{b}}\end{array}$

\section{Soleus}

Concentration $\left(\mathrm{CH}_{3}\right)$

$-0.016$

0.149

$0.312 *$

Concentration and composition $\left(\mathrm{CH}_{2}\right)$

0.153

$0.394 * *$

$0.477 * * *$

Composition $\left(\mathrm{CH}_{2}: \mathrm{CH}_{3}\right)$

0.217

$0.439 * * *$

$0.241^{*}$

Composition adjusted for quantity $\left(\mathrm{CH}_{2}: \mathrm{CH}_{3 \text { adj }}\right)$

$0.320^{*}$

$0.583 * * *$

$0.532 * * *$

\section{Tibialis Anterior}

Concentration $\left(\mathrm{CH}_{3}\right)$

0.200

0.205

$0.258 *$

Concentration and composition $\left(\mathrm{CH}_{2}\right)$

0.224

$0.338^{*}$

$0.344 * *$

Composition $\left(\mathrm{CH}_{2}: \mathrm{CH}_{3}\right)$

0.100

$0.337^{*}$

0.202

Composition adjusted for quantity $\left(\mathrm{CH}_{2}: \mathrm{CH}_{3}\right.$ adj $)$

0.218

$0.445^{* * *}$

$0.364 * *$

645

$* \mathrm{p}<0.05, * * \mathrm{p}<0.01, * * * \mathrm{p} \leq 0.001$

647 Tibialis anterior has ${ }^{\mathrm{a}} \mathrm{n}=50$ and ${ }^{\mathrm{b}} \mathrm{n}=64$.

648 HOMA-IR, Homeostasis Model Assessment of Insulin Resistance; IMCL, intramyocellular

649 lipid; $\mathrm{CH}_{3}$, methyl protons resonating at $0.9 \mathrm{ppm} ; \mathrm{CH}_{2}$, methylene protons resonating at 1.3

650 ppm; $\mathrm{CH}_{2}: \mathrm{CH}_{3}$, compositional saturation index calculated as the ratio of $\mathrm{CH}_{2}$ to $\mathrm{CH}_{3}$

651 resonances; $\mathrm{CH}_{2}: \mathrm{CH}_{3}$ adj, $\mathrm{CH}_{2}: \mathrm{CH}_{3}$ saturation index adjusted for lipid quantity.

652

653

654

655

656

657

658 